\title{
DISCUSSION
}

\section{Use of liquid limit state to generalize water retention properties of fine- grained soils}

\author{
L. N. REDDI and R. PODURI (1997). Géotechnique 47, No. 5, 1043-1049.
}

\section{F. A. M. Marinho and C. S. Pinto, University of São Paulo}

The writers would like to present some comments on the process of void ratio reduction used by the authors and how it is related to the point where the soil desaturates. Fig. 8(a) presents the idealization of a process in which the reduction in water content is due to the reduction in volume of the soil (mechanical consolidation) or vice versa (drying process). Consider a soil at point $\mathrm{A}$, which is at its liquid limit. The reduction in volume due to mechanical compression will follow the line AE. If the soil is allowed to dry from point $\mathrm{A}$, it will follow the line $\mathrm{AB}$ and will desaturate at $\mathrm{B}$. The suction at point $\mathrm{B}$ is called suction at the air entry point.

If a soil is consolidated up to point $\mathrm{E}$ and then allowed to dry, the desaturation point will be at the same point (i.e. point E). This is because the soil has passed the minimum volume that can be attained by drying. Fig. 8(b) illustrates some possible paths for soils during drying.

In order to obtain different suction at the air entry point, the water content after the consolidation must be lower than that equivalent to point $\mathrm{C}$ on Fig. 8(a). If the water content is higher than the water content at point $\mathrm{B}$, the air entry point should be the same for all samples of the same soil.

In Table 1 the authors presented what was called the air entry suction at LL. For the montmorilonite and for kaolinite it was $9.7 \mathrm{kPa}$ and $11 \mathrm{kPa}$, respectively. These points should be represented by point $\mathrm{B}$ when plotted as in Fig. 8(a). The pressure necessary to bring these two soils from a water content above the liquid limit to the liquid limit is about $10 \mathrm{kPa}$. When a sample isotropically consolidated is unloaded under undrained conditions, a suction is generated with a value equal to the pressure applied. This occurs because the soil is saturated and it can sustain this level of suction without desaturation occurring. It is hard to understand how a soil like montmorilonite will desaturate when unloaded from an effective stress of $11 \mathrm{kPa}$.

The slope of the relationship between water content and log (suction) varies with the plasticity of the soil and with its stress

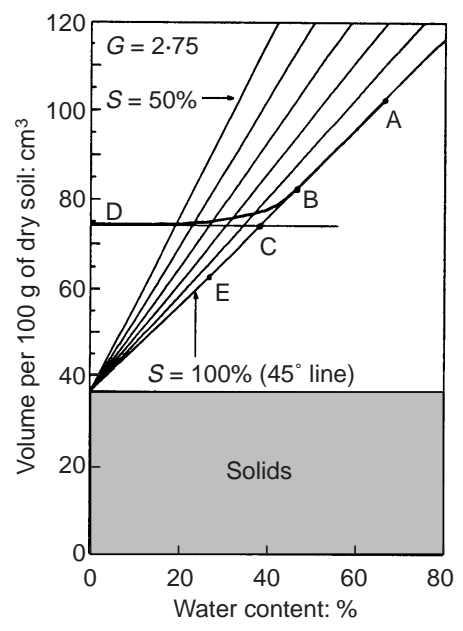

(a)

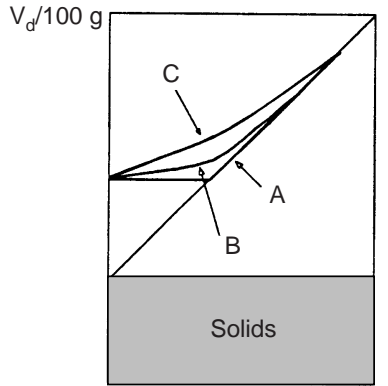

Water content: \%

(b)
Fig. 8. Representation of soil volume change as a function of water content reduction history (Marinho, 1994). The referred slope can be described as the reduction in water content (expressed in percentage) over one logarithmic cycle. This is called suction capacity $(C)$ (Marinho \& Chandler, 1993).

Figure 9 presents the results of drying tests and oedometer test (converted to water content), and a general trend can be observed. Samples from slurry are the upper limit for this relationship. This relationship is only valid for liquid limit higher than $25 \%$. If this is valid, the water content-suction relationship can be inferred using only one suction measurement. The liquid limit can give an indication of the water storage capacity of a soil, and it can be related to the pore size distribution index (Marinho \& Pinto, 1997).

The pore size distribution index $(\lambda)$ is defined as the slope of the relation between $\log (\Theta)$ and $\log$ (suction), according to Brooks \& Corey (1966), where

$$
\Theta=\frac{\theta-\theta_{\mathrm{r}}}{\theta_{\mathrm{s}}-\theta_{\mathrm{r}}}=\left\{\frac{\left(u_{\mathrm{a}}-u_{\mathrm{w}}\right)_{\mathrm{b}}}{\left(u_{\mathrm{a}}-u_{\mathrm{w}}\right)}\right\}^{\lambda}
$$

Equation 6 only applies for $\left(u_{\mathrm{a}}-u_{\mathrm{w}}\right) \geqslant\left(u_{\mathrm{a}}-u_{\mathrm{w}}\right)_{\mathrm{b}}$. The term $\left(u_{\mathrm{a}}-u_{\mathrm{w}}\right)_{\mathrm{b}}$ is the air entry value of suction, which should be equivalent to $\Psi_{\mathrm{a}}$, and $\theta_{\mathrm{r}}$ and $\theta_{\mathrm{s}}$ are the residual and saturated volumetric water content, respectively.

Using equation (5), the authors are assuming that the residual water content is zero. This implies that the adjustment of the experimental data is not the same as when the residual water content is considered, giving a different value for $\lambda$. Therefore, it is difficult to compare the values for the pore size distribution index directly. The writers would like to suggest the use of the filter paper technique to extend the level of suction obtained by the authors, allowing for the determination of the residual water content.

The order of magnitude of the $\lambda$ obtained by the authors is significantly different, not only from that obtained by the writers, but also from those in the literature. The experimental data reported by the authors refer to degree of saturation above $60 \%$. At this level of suction, the soil may still be shrinking and the model does not apply.

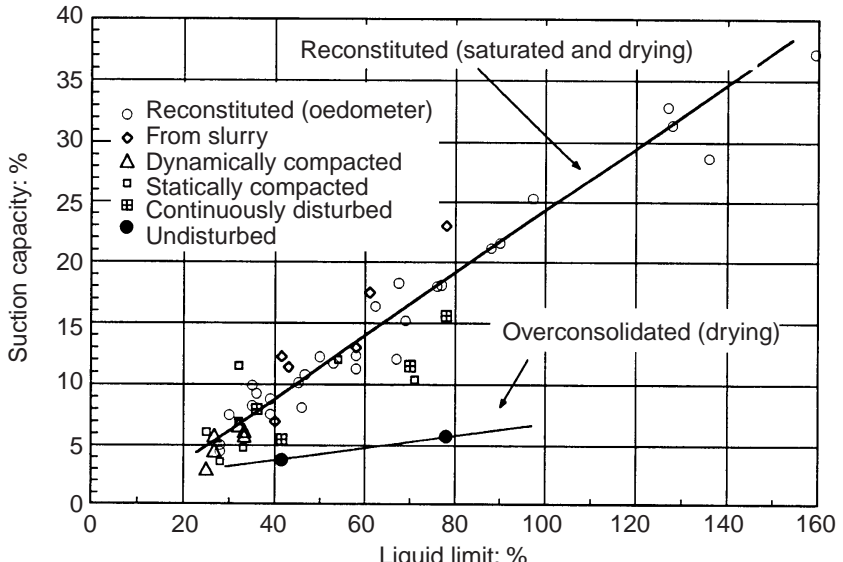

Fig. 9. Relationship between suction capacity and liquid limit for different types of sample (Marinho, 1994) 
A relation between $\lambda$ (obtained using equation (6)) and liquid limit is shown in Fig. 10. The results presented are for different types of soil and three different kinds of sample (i.e. samples from slurry, undisturbed samples and statically compacted samples). Although there is some scatter in the data, two lines may be drawn, one relating to the points of undisturbed samples and another relating to the points of samples from slurry. The undisturbed line may be an upper limit and the slurry line a lower limit for this kind of relationship. More research is needed in order to identify the effect of the OCR of the soil on the pore size distribution index.

\section{Author's reply}

The authors thank the writers for their interest in the paper and for their thoughtful comments. It must be pointed out at the outset that the Technical Note was not concerned with the relationship between reduction in volume of soil and the water content reduction associated with this soil volume change. In the authors' study, the samples were consolidated and brought to liquid limit state void ratios prior to using air pressures to extract moisture. The writers' viewpoint of correlating LL (liquid limit) and $\lambda$ is fundamentally different from the authors' intent of looking at the general water retention behaviour of soils at liquid limit state void ratios and relating the behaviour at other states to the liquid limit state behaviour.

It must also be pointed out that the air-entry retention values reported in the paper were determined by interpolating the experimental observations. They might have also suffered from any errors resulting from the transfer of the soil samples from consolidometers to pressure plate extractors and the possible swelling associated with this transfer.

The $\lambda$ values reported in the paper were based on a simplified equation (equation (5)) that does not consider residual volumetric water contents. The discrepancies between the values reported in this paper and those reported by others are primarily because of this limitation, as the writers aptly remarked. Experiments involving higher suctions to identify residual water contents are in progress.

The correlations between LL and suction capacity and $\lambda$ (Figs 9 and Fig. 10) indicate that LL is a valuable intrinsic parameter of soils that reflects the water retention character of soils. They do not, however, help us in our study of water

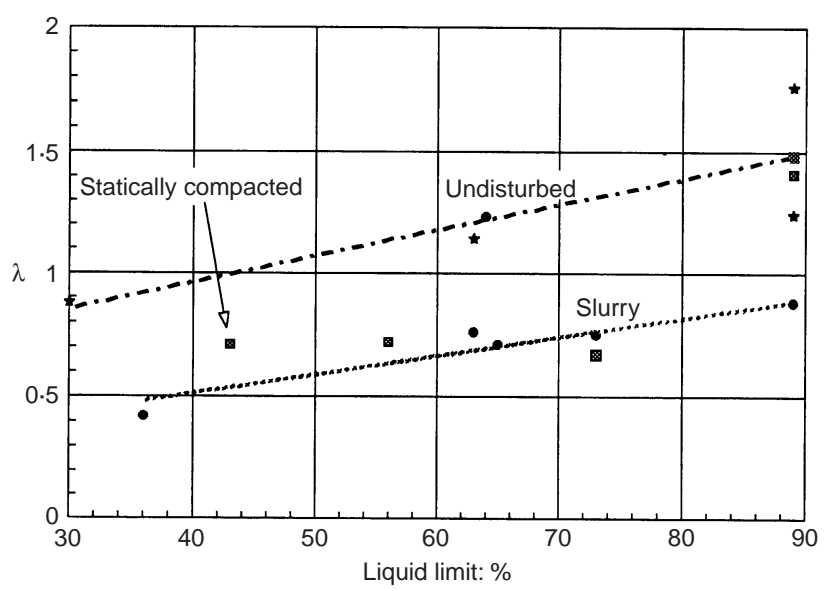

Fig. 10. Relation between $\lambda$ and liquid limit for three types of sample

retention characteristics at liquid limit state. Also, for a given liquid limit (i.e. for a given soil), $\lambda$ and suction capacity may not be unique, as seen in the scatter in Fig. 9 and in the data corresponding to $\mathrm{LL}=88$ in Fig. 10. This was because of the different states of the samples resulting from the differences in the type and nature of compaction and/or consolidation. Examination of these issues was the underlying focus of the paper.

\section{REFERENCES}

Brooks, R. H. \& Corey, A. T. (1966). Properties of porous media affecting fluid flow. J. Irrigation Drainage Div., ASCE 61-87.

Marinho, F. A. M. (1994). Shrinkage behaviour of some plastic clays. $\mathrm{PhD}$ thesis, Imperial College, University of London.

Marinho, F. A. M. \& Chandler, R. J. (1993). Aspects of the behaviour of clays on drying. In Unsaturated soils, (edited by S. L. Houston and W. K. Wray), pp. 77-90. ASCE Geotechnical Special Publication no. 39.

Marinho, F. A. M. \& Pinto, C. S. (1997). Evaluation of pore size characteristic of plastic soils. Third Brazil. Symp. Unsaturated Soils, Rio de Janeiro 1-11. 